ISBN 978-93-86878-30-4

13th PORTO International Conference on Economics, Disaster Management and Interdisciplinary

studies (PEDMIS-19)

Porto (Portugal) Sept.9-11, 2019

\title{
Mortgage Loans' Determinants - Empirical Evidence From Romania
}

\author{
Iustina Alina Boitan ${ }^{1}$ and Ionela Costica ${ }^{2}$ \\ ${ }^{1,2}$ Bucharest University of Economic Studies, Faculty of Finance and Banking, Romania
}

\begin{abstract}
By this study we intend to provide an insight into the main culprits of Romanian households' housing affordability. Traditionally, population's wealth is represented by financial assets (cash, bank deposits, sovereign bonds, life insurances, pension funds) and nonfinancial assets, namely residential real estates. The presence of the latter in the population's asset portfolio is an indicative of their living conditions. The rationale of the study is to proxy population's intention to purchase a property, or, in other words, the demand for housing, by the growth rate of mortgage loans. Hence, a pattern of persistent increase in mortgage loans should depict the stringent need or desire of raising the personal wealth and improving the degree of social security. Further, it had been considered a series of key economic and financial indicators, as well as two subjective sentiment indicators (the systemic financial stress indicator and the economic sentiment indicator) in order to empirically examine, by means of a multivariate regression, the extent to which they influence Romanian households' demand for housing, proxy by the level of mortgage loans. The time period considered covered the timeframe January 2007 - May 2019, all variables exhibiting monthly frequency. The findings indicated that the level of households' earnings, households' savings and the mortgage loans' interest rate exhibit a statistically significant influence on the level recorded by mortgage loans. In addition, both sentiment indicators (one focused exclusively on the financial sector and the other one covering the economic sectors) generated an impact on households' desire to apply for a mortgage loan.
\end{abstract}

Keywords: mortgage loans, mortgage interest rate, earnings, savings, economic sentiment, financial stress, multivariate regression.

\section{Introduction}

In the last decade, the Romanian residential real estate market has witnessed a rapid pace of growth, fuelled by the structural deficit that persistently characterizes this market. The high positive dynamics of households' demand for housing was supported mainly by:

- the slowdown of the nominal interest rate, a trend imposed on by the progressive reduction of the monetary policy interest rate;

- higher asset prices increased the value of the collateral, meaning a higher amount of borrowed funds;

- $\quad$ the exchange rate appreciation trend;

- the high availability of loans, due to relaxed monetary policy and to the increasing competition between foreign-owned banks. The joint action of these two factors has increased the affordability of credit standards;

- the increasing confidence in the ongoing improvement of macroeconomic framework and in the disinflationary process;

- optimistic expectations relative to the increase of disposable income. In this respect, the process of EU integration has been perceived as a catalyst towards the raising of the convergence pace with the member states; 
- $\quad$ subjective, psychological factors represented by the social security need felt by individuals to own a residential property instead of renting one. In this respect it should be mentioned that according to Eurostat most recent statistics, Romania places itself on the first position among EU member states regarding the share of population living in owner-occupied dwellings (96.8\%);

- regulation. As of 1 January 2019, new provisions regarding the computation and use of a benchmark index for floating-rate loans granted to consumers entered into force. This recent change is expected to trigger effects on the mortgage market in the near timeframe.

The favourable macroeconomic and financial outlook has induced a positive perception relative to the strengthening of living conditions in the future. This belief can be reflected by the path recorded by households' indebtedness degree, which rose in few years from $40 \%$ to near $60 \%$ and focused on two directions: consumer loans and mortgage loans. Both of them provide a picture of the degree of population's endowment with durable goods and, respectively, with residential real assets.

Our research aims to shed light on the leading factors that explain the dynamics of the Romanian mortgage market, by focusing on households' housing demand. It is aimed to assess to what extent it is driven by households' net earnings, the interest rate perceived for mortgage lending and households' savings, as well as by several economic sentiment indicators. The time period considered for this study exhibits a monthly frequency and covers January 2007 - May 2019.

By this study, it is proposed a larger framework, in which the focus is on the housing demand and its determinants. It is used a series of economic and financial indicators to provide empirical insight into the issue of Romanian households' housing demand.

\section{Literature Review}

Most studies in the international economic literature have strictly examined the leading factors of the house price dynamics (e.g. Egert and Dubravko, 2007), but haven't put this concept in relation with households' affordability to buy a house, to reveal the degree of causality. Sorensen and Lichtenberger (2007) investigated the financial and institutional determinants of the mortgage interest rates heterogeneity across euro area countries and uncovered that a large part of this heterogeneity is due to country-specific differences in the regulatory and fiscal framework of the mortgage markets. Milani (2010) followed the same research direction and obtained that factors such as the cost of deposits, the level of guarantees given, the intensity of the bankcustomer relationship and the efficiency of the civil justice system exert the most influence on mortgage interest rates, while banking system degree of competitiveness does not affect interest rates.

Wolswijk (2006) argues that real mortgage debt in EU-15 countries "is affected by mortgage interest costs, by house prices, financial deregulation and stock markets, while the effects of household disposable income and inflation are less evident".

Another strand of literature compares European with US and UK mortgage markets, in terms of regulations, financial structures, accounting and statistical frameworks (European Central Bank, 2009). The share of households with mortgages exhibits the highest heterogeneity in euro area, being directly correlated with income levels.

With respect to the Romanian mortgage loans market, the studies made by international organizations, such as the European Mortgage Federation - EMF, show that this market segment has a high growth potential. The key figures for the first quarter of 2019 indicate a growth pattern of both outstanding and gross mortgage debt, almost all mortgages being granted in the national currency. House prices recorded too, a steep increase on a year-on-year basis till 2018. Starting with 2019, the residential property price index compressed its growth rate, on the background of decreasing volumes of residential construction and a decline in the residential real estate transactions (EMF, 2019). 


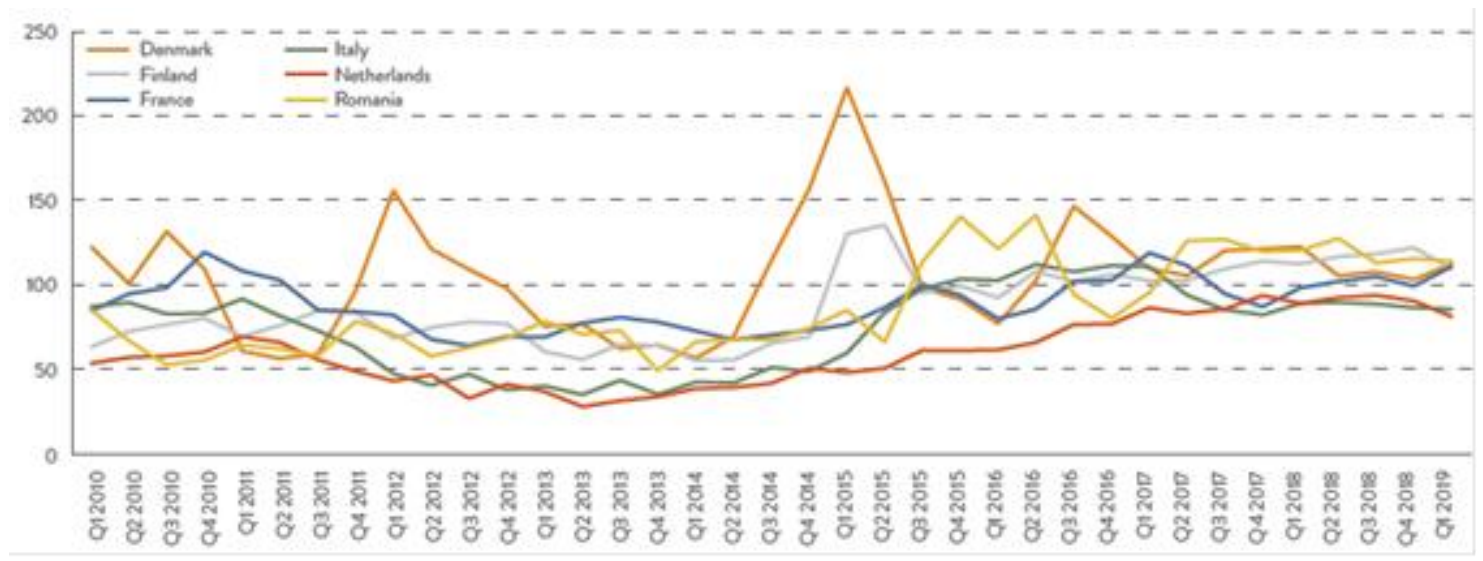

Fig. 1: Gross mortgage lending - increases between $80 \%$ and $120 \%$ of 2007 levels Source: European Mortgage Federation, Quarterly Review, Q1, 2019

As some empirical studies state, within the EU can be identified two groups of countries: one group with poorly developed and heavily regulated mortgage markets, characterized by a low share of mortgage loans to GDP (it is the case of Romania), and a second group of countries with deregulated mortgage markets and a high level of the ratio mentioned above. Generally speaking, countries with market based financial systems, for which the capital market actively provides long term financing, as an alternative to customers' deposits, and diminishes the mismatch between assets and liabilities maturity, are characterized by an active role of mortgage market, and, implicitly, are exposed to a greater extend to the process of liberalization and deregulation.

\section{Research method and results obtained}

The aim of the study consists of a country-level empirical analysis of the housing demand determinants. In this respect, it has been considered the indicators: real earnings index (the ratio between the average net nominal earning index and general consumer price index), interest rate perceived for mortgage loans and households' term deposits, and two sentiment indicators: the systemic financial stress indicator CISS computed and monitored by the European Central Bank and the economic sentiment indicator ESI calculated by Eurostat.

The dependent variable is the gross level of mortgage loans, as a proxy for the housing demand. All variables have been, first, the subject of stationarity, seasonal adjustment and multicollinearity tests. The unit root test $\mathrm{ADF}$ indicated that all variables are stationary in first difference. There is no evidence of multicollinearity between explanatory variables. Further, to assess their explanatory power, it has been employed the multiple regression, in order to identify the potentially important determinants.

The time period considered is 2007-2019 in order to capture the impact the global financial crisis had on Romanian housing demand. A first insight is provided by chart 2 below, which illustrates the persistent rising trend of both households' savings and mortgage lending. 


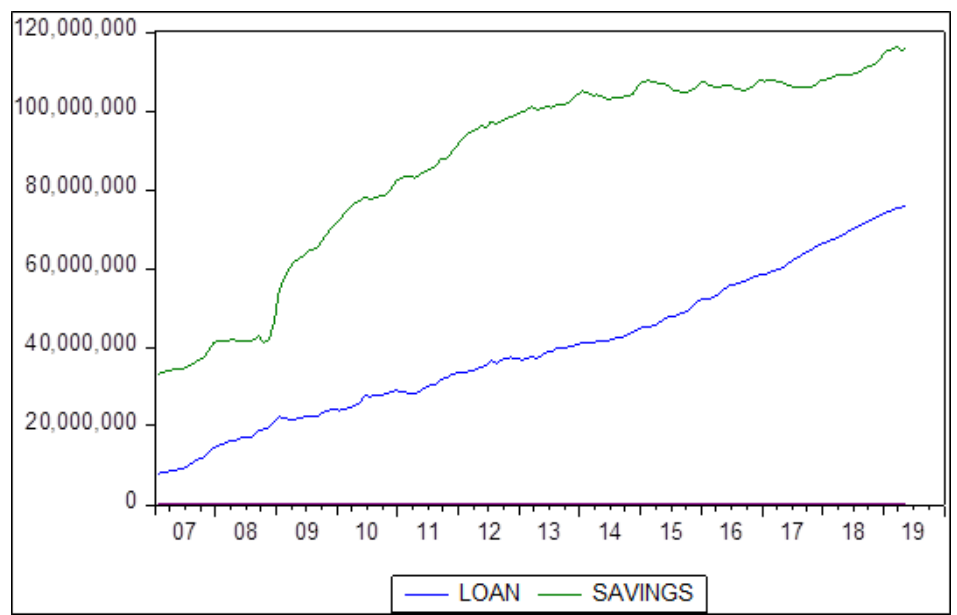

Fig. 2: Time path of Romanian mortgage lending and savings

Source: author, data collected from National Bank of Romania database

Table 1 reports the primary descriptive statistics for each variable considered, which emphasize that no variable follows a normal distribution.

TABLE I: Descriptive Statistics

\begin{tabular}{lcccccc}
\hline & Loans & Savings & $\begin{array}{c}\text { Interest } \\
\text { rate }\end{array}$ & Earnings & CISS & ESI \\
\hline Mean & 39487319 & 87326478 & 7.70 & 10.52 & 0.23 & 99.27 \\
Median & 37402358 & 100000000 & 7.59 & 8.70 & 0.16 & 101.90 \\
Maximum & 75956373 & 116000000 & 14.76 & 25.80 & 0.78 & 114.50 \\
Minimum & 7902876 & 32872718 & 3.62 & 0.10 & 0.03 & 68.30 \\
Std. Dev. & 18502715 & 25377156 & 3.03 & 6.76 & 0.19 & 10.29 \\
Skewness & 0.26 & -0.97 & 0.26 & 0.55 & 1.10 & -0.95 \\
Kurtosis & 2.12 & 2.53 & 1.81 & 2.31 & 3.40 & 3.60 \\
Jarque-Bera & 6.53 & 24.91 & 10.51 & 10.44 & 31.03 & 24.91 \\
Probability & 0.04 & 0.00 & 0.01 & 0.01 & 0.00 & 0.00 \\
Observations & 149 & 149 & 149 & 149 & 149 & 149 \\
\hline \hline
\end{tabular}

The spread around the mean is considered a clue of sample heterogeneity and is assessed by means of standard deviation statistics. The lowest standard deviation belongs to CISS indicator and can be interpreted as a relatively stable financial environment, from the standpoint of systemic financial stress and vulnerabilities. At the opposite is the economic sentiment indicator ESI for which the raw values are scattered around sample's mean. In this case, the large value recorded by the standard deviation suggests the presence of extreme values in the sample.

The shape of the distribution function is illustrated by the skewness and kurtosis statistics. In theory, the presence of a normal distribution is signaled by the accomplishment of the following thresholds: skewness equal to zero and kurtosis equal to 3 . Savings and the economic sentiment indicator exhibit negative asymmetry (skewness of -0.97 , respectively of -0.95 ), thus the two time series depict a longer tail towards left indicating that smaller values predominate in the sample. Kurtosis lies below the theoretical threshold for 4 out of 6 variables, and hence the time series are flatter than a normal distribution (platikurtotic). The two sentiment indicators exhibit a kurtosis larger than 3, therefore the time series' distribution function is higher than the normal one.

Another statistical test for uncovering the presence of a normal distribution is the Jarque-Bera test. The implicit null hypothesis is that the series is normally distributed. In our case the probability assigned to JarqueBera statistic is close to $0.000 \%$, thus the null hypothesis is rejected so all the time series do not follow a normal distribution.

Then, it has been applied a unit root test (Augmented Dickey-Fuller test) to reveal the stationary features of the time series. All variables are stationary in first difference. 
The results of the multiple regression analysis are synthesized in table 2.

TABLE II: Regression Results

Dependent Variable: DLOG(LOAN)

Method: Least Squares

Sample (adjusted): 2008M02 2019M05

Included observations: 136 after adjustments

\begin{tabular}{lrlrr}
\hline \hline \multicolumn{1}{c}{ Variable } & Coefficient & Std. Error & t-Statistic & Prob. \\
\hline \hline DLOGSAVINGS & 0.29894 & 0.064085 & 4.664757 & 0 \\
DEARNING(-6) & -0.0015 & 0.000533 & -2.82178 & 0.0055 \\
DINTEREST & 0.007365 & 0.003016 & 2.442063 & 0.0159 \\
DESI(-9) & 0.00151 & 0.000744 & 2.03025 & 0.0444 \\
DCISS(-12) & 0.045474 & 0.021662 & 2.099236 & 0.0377 \\
C & 0.009881 & 0.001263 & 7.822491 & 0 \\
\hline \hline R-squared & 0.288331 & Mean dependent var & 0.011976 \\
Adjusted R-squared & 0.260959 & S.D. dependent var & 0.015748 \\
S.E. of regression & 0.013538 & Akaike info criterion & -5.723526 \\
Sum squared resid & 0.023826 & Schwarz criterion & -5.595026 \\
Log likelihood & 395.1997 & Hannan-Quinn criter. & -5.671307 \\
F-statistic & 10.53385 & Durbin-Watson stat & 1.526556 \\
Prob(F-statistic) & 0 & & & \\
\hline \hline
\end{tabular}

All the five explanatory variables are statistically significant for a cut-off probability of $5 \%$ and excepting households' earnings, they exhibit a positive sign. Thus, an increase of their level is followed by an increase of the mortgage lending. In case of economic sentiment indicator, the above mentioned relationship stands for improvements in indicator's value with 9 months prior to the receiving of the loan. As regards the financial stress indicator CISS, it will exert an impact on the mortgage lending level with a lag length of 12 months. The higher the value of the estimated coefficient, the broader the influence exerted by the explanatory variable on the dependent one (mortgage lending). The findings illustrate that households' savings rate triggers most impact on the amount of lending, while earnings exhibit a negligible impact. It means that not the amount of the revenue is determinant for the decision to apply for a long-term mortgage loan. Instead, people's ability to save a specific amount from their monthly revenue encourages them most in engaging in a loan contract.

The correlogram of residuals indicates that residuals are not serially correlated. Additional information on whether estimated data are well fitting actual data is gained by generating residuals pattern graph (figure 3 below). 


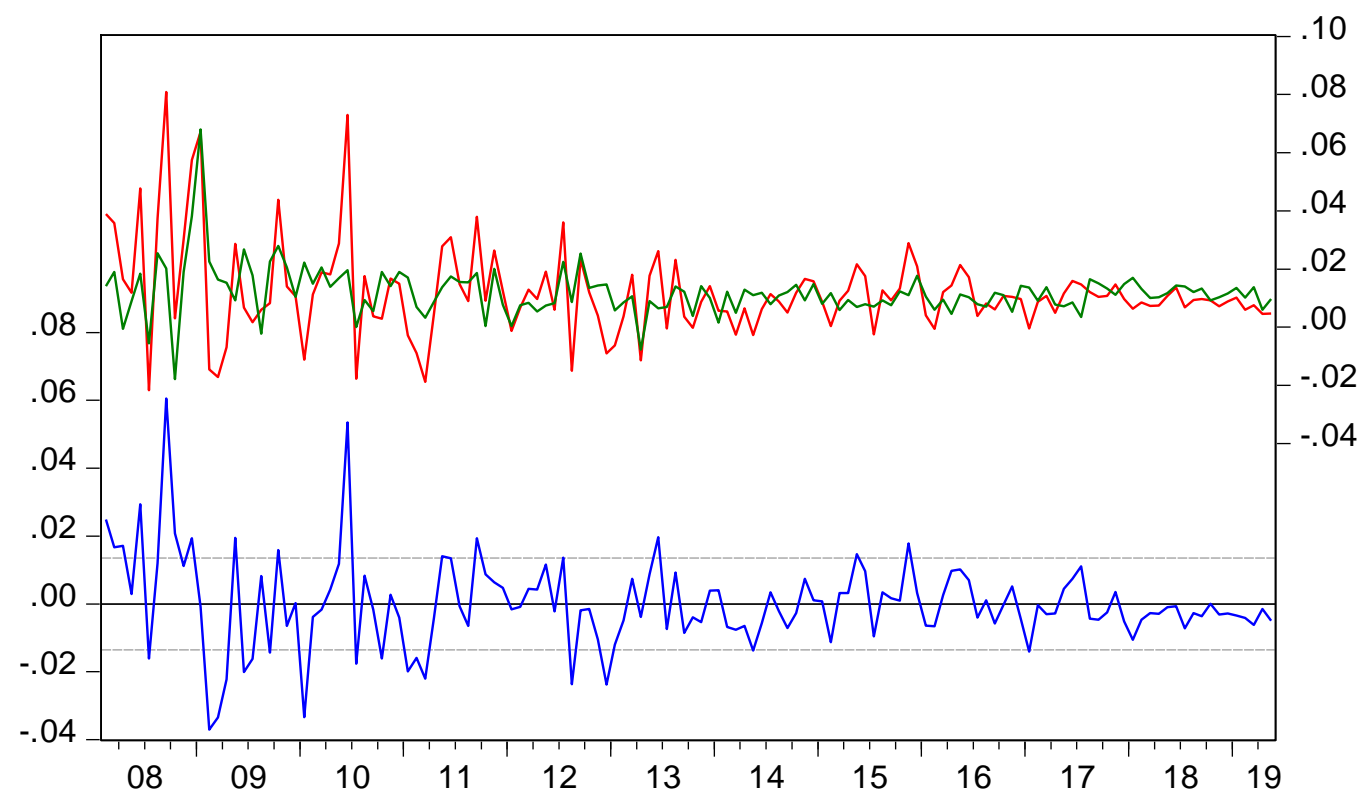

- Residual _ Actual _ Fitted

Fig. 3: Residual, actual and fitted values

As there are no sharp upward or downward jumps of fitted (forecasted) values against actual ones, or of residuals against the horizontal line one may conclude that the fitted values are matching the long run features of actual data. Also, the residuals exhibit a flatter pattern with the passing of time, which is beneficial for model's goodness-of-fit. A last goodness-of-fit test aims at investigating whether the estimated coefficients are stable. It has been employed the CUSUM test for the regression error term. As figure 4 depicts, the sum of recurrent errors fluctuates within the area defined by the two critical lines of 5\% significance, meaning that equation's coefficients are stable.

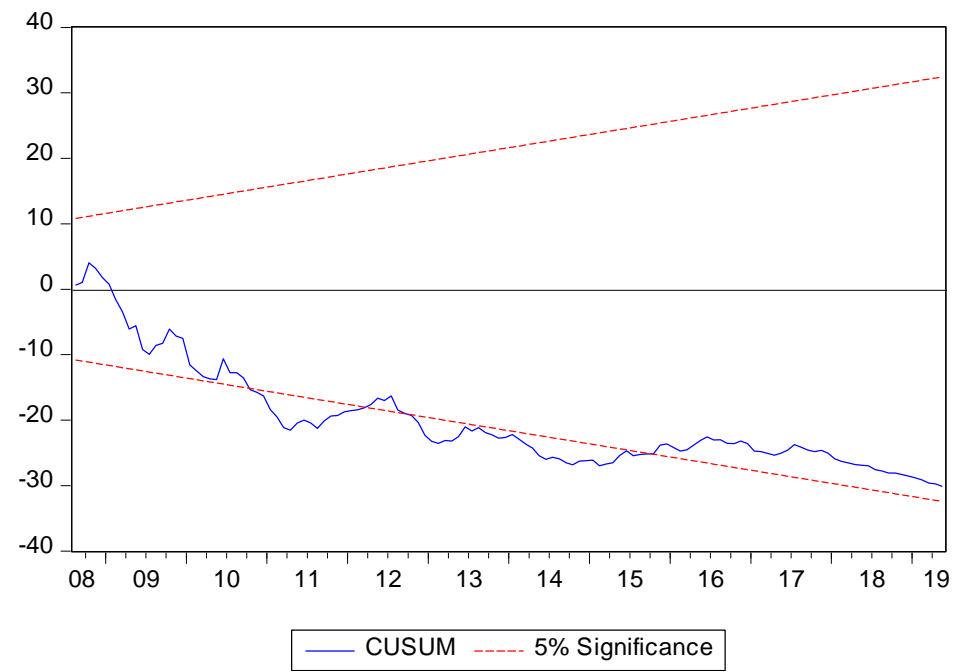

Fig. 4: Coefficients' stability test

\section{Conclusions}

The paper had investigated the determinants of mortgage loans in order to better understand the proportion to which economic, financial and public perception factors prevail in taking the decision of purchasing a house. Therefore, this empirical approach is meant to make the national authorities more aware of the importance of 
properly calibrating the macroeconomic mix of policies, especially those related to monetary, fiscal and income policy, because of the strong interdependencies between real and financial sector. Imposing a restrictive nature of these policies will diminish population's disposable income, and, if overlapped on a high degree of indebtedness, will increase its vulnerability in terms of bank debt repayment. Households' repayment difficulties will be transferred to the credit institutions' balance sheet, affecting the quality of their loan portfolio and, ultimately, will contribute to the erosion of the profitability and prudential indicators, putting pressure on the stability and soundness of the entire banking system.

In the context of the 2008 financial turmoil which overlapped on a real estate boom and burst, this analysis will serve as a starting point for debates and greater engagement on the part of policymakers and banks, in order to improve people's access to banking financing and re-launch sound mortgage lending.

\section{References}

[1] B. Égert and M. Dubravko, "Determinants of house prices in central and Eastern Europe", BIS Working Papers No 236, Monetary and Economic Department, September 2007.

[2] European Central Bank, "Housing finance in the euro area", ECB Structural Issues Report, March 2009.

[3] European Mortgage Federation (EMF), “Quarterly review of European mortgage markets”, Q1, 2019.

[4] C. Milani, "The Determinants of Mortgage Interest Rates: An Empirical Analysis of the Euro Area Countries", Temi di Economia e Finanza Working Paper No. 2, June 30, 2010.

https://doi.org/10.2139/ssrn.1687653

[5] C.K. Sorensen and J.D. Lichtenberger, "Mortgage Interest Rate Dispersion in the Euro Area", ECB Working Paper Series no. 733, February 2007.

[6] G.Wolswijk, "Determinants of Mortgage Debt Growth in EU Countries", European Journal of Housing Policy, vol. 6(2), pp.131-149, February 2006.

https://doi.org/10.1080/14616710600787627 